Network Working Group

Request for Comments: 4688

S. Rushing

Category: Informational

\title{
A Uniform Resource Name (URN) Namespace for Aerospace and Defence Industries Association of Europe (ASD) Specification $1000 \mathrm{D}$
}

Status of This Memo

This memo provides information for the Internet community. It does not specify an Internet standard of any kind. Distribution of this memo is unlimited.

Copyright Notice

Copyright (C) The Internet Society (2006).

Abstract

This document describes a Uniform Resource Name (URN) namespace for naming persistent resources defined by Aerospace and Defence Industries Association of Europe (ASD) Specification 1000D.

Table of Contents

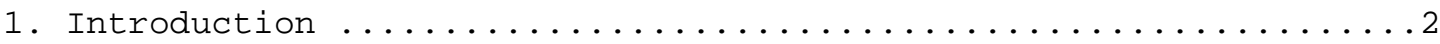

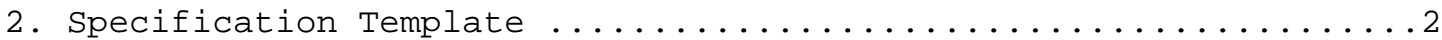

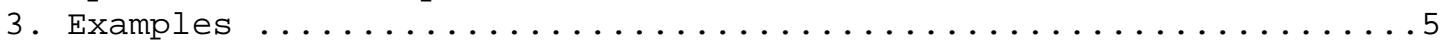

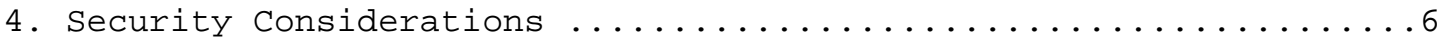

5. Namespace Considerations and Community Considerations .......6

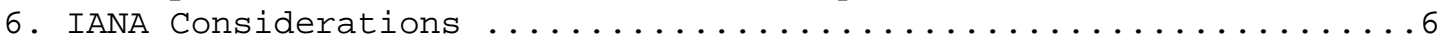

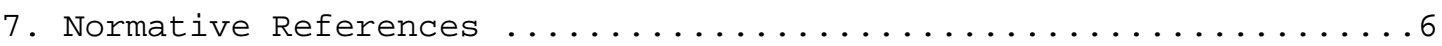




\section{Introduction}

Specification 1000D [1] (S1000D) is an international specification for the procurement and production of technical publications. The current issue of the specification has been jointly produced by the Aerospace and Defence Industries Association of Europe (ASD; previously AECMA, European Association of Aerospace Industries) and the Aerospace Industries Association of America (AIA). The specification is used worldwide by a variety of commercial and government entities for the development of technical documentation.

The specification adopts ISO, Computer-Aided Acquisition and LifeCycle Support (CALS), and W3C standards to promote document standardization in which information is generated in a neutral format. Compliant documentation generated using the specification can be processed on different, and often disparate, IT systems. It is this feature, added to the concept of modularization, that makes the specification acceptable to the wider international community.

Portions of S1000D define a resource coding system allowing resources created under the specification to be uniquely identified in global environment. To provide for the creation of a web-based resource management system, ASD would like to assign URNs [2] [3] [4] to resources created under the specification in order to retain unique, permanent, location-independent names for these resources, in addition to providing a framework for resolution of these resources.

For more information about ASD and S1000D, see http://WwW.s1000d.org.

This namespace specification is for a formal namespace.

2. Specification Template

Namespace ID:

To be assigned. Request the string "S1000D".

Registration information:

Version 2

Date: <2005-03-7, when submitted>

Declared registrant of the namespace:

Name :

ASD TPSMG Chairperson 
Address :

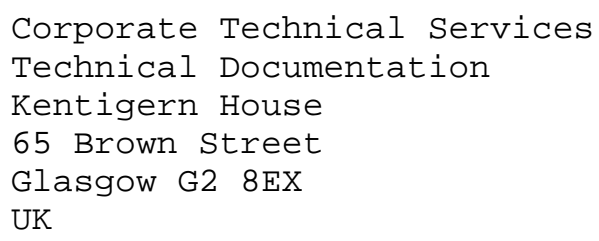

Contact :

Mr. Dennis Hoyland

E-mail: adctsetechinfo.mod.uk

Declaration of structure:

The identifier has the following ABNF [5] structure.

; start ABNF notation

URN = "URN:" namespace NSS

namespace = "S1000D:"

$\begin{aligned} \text { NSS }= & \text { dmc-nss / pmc-nss / csn-nss / icn-nss } \\ & \text { com-nss / ddn-nss / dml-nss }\end{aligned}$

; Define the subnamespace as an subnamespace identifier

; plus a subnamespace code string

dmc-nss = "DMC-" nss-code

pmc-nss = "PMC-" nss-code

csn-nss $=$ "CSN-" nss-code

icn-nss $=$ "ICN-" nss-code

com-nss $=$ "COM-" nss-code

ddn-nss $=$ "DDN-" nss-code

dml-nss $=$ "DML-" nss-code

; Define the subnamespace code as a string encoded to the ; format specified by the namespace identifier and an ; optional extension string indicating the resource status. nss-code $=$ subcode subext

; The code strings are a groups of alpha and digit characters ; separated by the dash character. The specific code syntax ; for each subnamespace is described in ASD specification 1000D. subcode $=1 *($ DIGIT / ALPHA / "-")

; Define the encoding extension as an optional set of status ; indicators separated by the "-" character. subext $=$ [issue] [lang] issue = "I-" 3DIGIT 


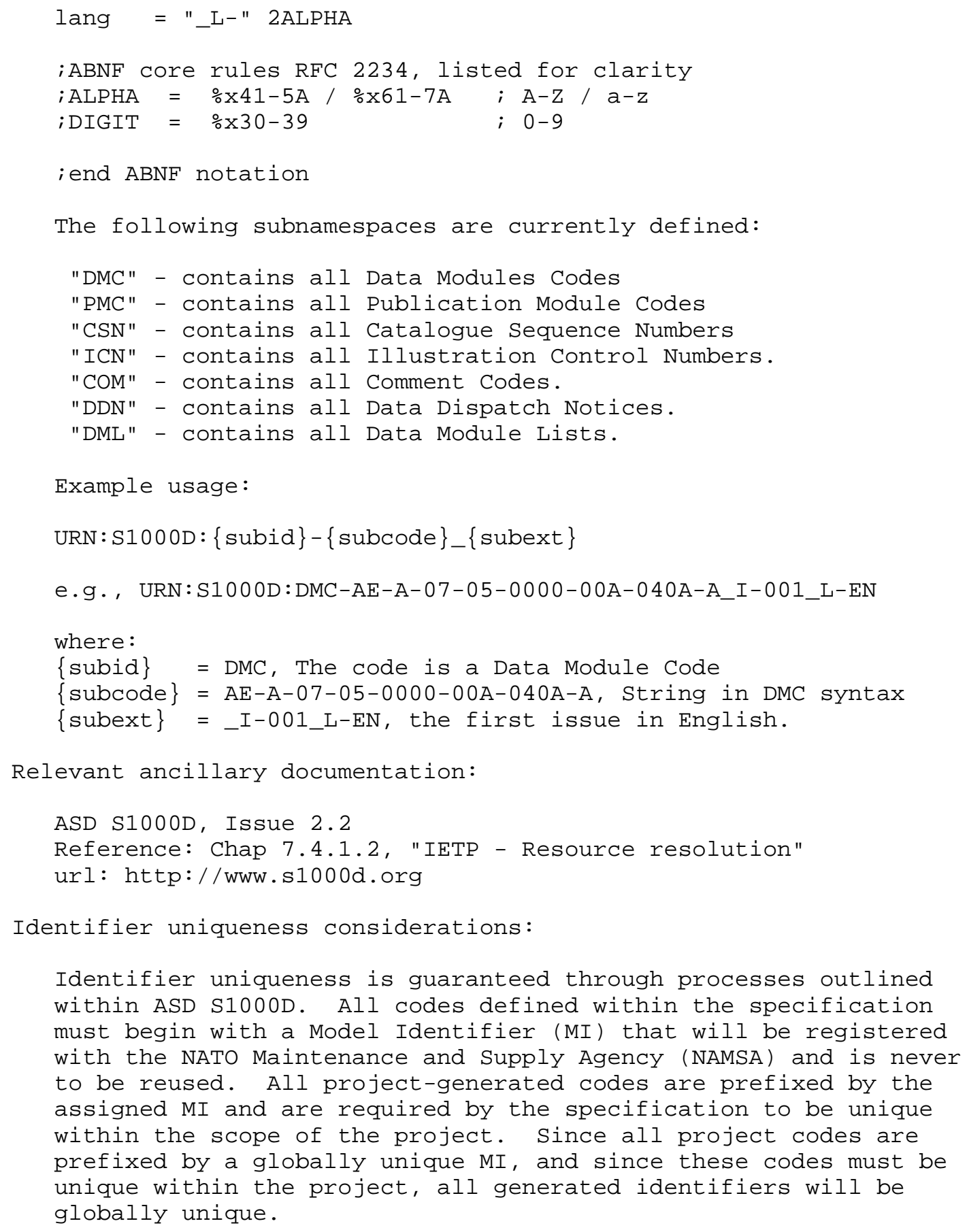


Identifier persistence considerations:

Persistence of identifiers is dependent upon suitable delegation of resolution and the fact that generated identifiers are to be persistent once published. Existing information objects can be used in new projects by referencing them through their persistent identifiers.

Process of identifier assignment:

Identifiers are assigned in the following manner. Projects are assigned a Model Identifier by the NAMSA organization. Projects then generate identifiers using the processes outlined in ASD S1000D. The codes are prefixed with the encoding identifier and possibly postfixed by the extension status identifiers.

Process for identifier resolution:

The project identified by the Model Identifier is responsible for providing a method of resource resolution. A suggested method of resolution is outlined in ASD S1000D.

Rules for Lexical Equivalence:

All generated identifiers are to be considered case-insensitive.

Conformance with URN syntax:

No special considerations.

Validation mechanism:

Identifiers must conform to ASD S1000D.

Scope:

Global.

3. Examples

The following examples are not guaranteed to be real and are provided for illustrative purposes only.

URN : S1000D : DMC-AE-A-07-04-0101-00A-040A-A

URN : S1000D:DMC-AE-A-07-05-0000-00A-040A-A_I-001_L-EN

URN : S1000D : ICN-AE-B-291101-M-C0419-00571-A-01-1

URN : S1000D : PMC-AE-F6117-00001-00 


\section{Security Considerations}

There are no additional security considerations other than those normally associated with the use and resolution of URNs in general.

5. Namespace Considerations and Community Considerations

Resources will be named and maintained in accordance with the processes described in this document, in addition to the processes described in S1000D. Any organization or individual can utilize the specification to create resources described by S1000D. Resolution and/or use of created resources is unrestricted by the specification in order to promote widespread adoption of open ASD standards, although organizations creating resources may control them as they see fit.

6. IANA Considerations

This document describes a "S1000D" URN NID registration for the S1000D organization and has been entered into the IANA registry of URN NIDs (http://wWw.iana.org/assignments/urn-namespaces).

7. Normative References

[1] "ASD Specification 1000D", May 2005.

[2] Moats, R., "URN Syntax", RFC 2141, May 1997.

[3] Berners-Lee, T., Fielding, R., and L. Masinter, "Uniform Resource Identifier (URI): Generic Syntax", STD 66, RFC 3986 , January 2005 .

[4] Daigle, L., van Gulik, D., Iannella, R., and P. Faltstrom, "Uniform Resource Names (URN) Namespace Definition Mechanisms", BCP 66, RFC 3406, October 2002 .

[5] Crocker, D. and P. Overell, "Augmented BNF for Syntax Specifications: ABNF", RFC 4234, October 2005. 


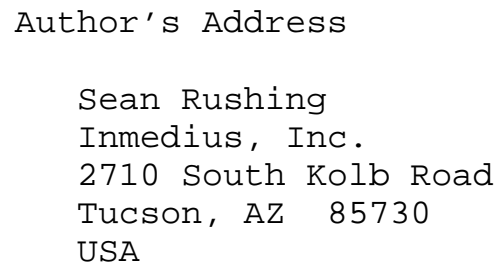

EMail: srushing@inmedius.com 
Full Copyright statement

Copyright (C) The Internet Society (2006).

This document is subject to the rights, licenses and restrictions contained in BCP 78, and except as set forth therein, the authors retain all their rights.

This document and the information contained herein are provided on an "AS IS" basis and THE CONTRIBUTOR, THE ORGANIZATION HE/SHE REPRESENTS OR IS SPONSORED BY (IF ANY), THE INTERNET SOCIETY AND THE INTERNET ENGINEERING TASK FORCE DISCLAIM ALL WARRANTIES, EXPRESS OR IMPLIED, INCLUDING BUT NOT LIMITED TO ANY WARRANTY THAT THE USE OF THE INFORMATION HEREIN WILL NOT INFRINGE ANY RIGHTS OR ANY IMPLIED WARRANTIES OF MERCHANTABILITY OR FITNESS FOR A PARTICULAR PURPOSE.

Intellectual Property

The IETF takes no position regarding the validity or scope of any Intellectual Property Rights or other rights that might be claimed to pertain to the implementation or use of the technology described in this document or the extent to which any license under such rights might or might not be available; nor does it represent that it has made any independent effort to identify any such rights. Information on the procedures with respect to rights in RFC documents can be found in BCP 78 and BCP 79 .

Copies of IPR disclosures made to the IETF Secretariat and any assurances of licenses to be made available, or the result of an attempt made to obtain a general license or permission for the use of such proprietary rights by implementers or users of this specification can be obtained from the IETF on-line IPR repository at http://www.ietf.org/ipr.

The IETF invites any interested party to bring to its attention any copyrights, patents or patent applications, or other proprietary rights that may cover technology that may be required to implement this standard. Please address the information to the IETF at ietf-ipreietf.org.

Acknowledgement

Funding for the RFC Editor function is provided by the IETF Administrative Support Activity (IASA). 